\title{
Teaching social perspective taking: how educators might learn from the Army
}

\section{Citation}

Gehlbach, Hunter, Lissa V. Young, and Linda K. Roan. 2012. "Teaching social perspective taking: how educators might learn from the Army." Educational Psychology 32 (3) (May): 295-309. doi:10.1080/01443410.2011.652807. http://dx.doi.org/10.1080/01443410.2011.652807.

\section{Published Version}

doi:10.1080/01443410.2011.652807

\section{Permanent link}

http://nrs.harvard.edu/urn-3:HUL.InstRepos:11384948

\section{Terms of Use}

This article was downloaded from Harvard University's DASH repository, and is made available under the terms and conditions applicable to Open Access Policy Articles, as set forth at http:// nrs.harvard.edu/urn-3:HUL.InstRepos:dash.current.terms-of-use\#OAP

\section{Share Your Story}

The Harvard community has made this article openly available.

Please share how this access benefits you. Submit a story.

Accessibility 
Running head: TEACHING PERSPECTIVE TAKING

\title{
Teaching Social Perspective Taking:
}

\section{How Educators might Learn from the Army}

\author{
Hunter Gehlbach and Lissa V. Young \\ Harvard University \\ Linda Roan \\ eCrossCulture
}

Word Count: 5758

Author Note

Hunter Gehlbach, Harvard Graduate School of Education, Harvard University;

Lissa V. Young, Harvard Graduate School of Education, Harvard University; and Linda Roan, eCrossCulture, Boulder, CO.

This research was funded by the U.S. Army Research Institute for the Behavioral and Social Sciences under Contract W91WAW-08-C-0046. The view, opinions, and/or findings contained in this paper are those of the authors and should not be construed as an official Department of the Army position, or decision. Kimberly Metcalf, Beret Strong and Mark Yager provided invaluable assistance in helping to collect these data. We also thank Andi O'Conor for her contribution in teaching the curriculum. This manuscript was greatly improved thanks to feedback from Hahrie Han.

Please address all correspondence to Hunter Gehlbach:

Hunter_Gehlbach@gse.harvard.edu. 
Running head: TEACHING PERSPECTIVE TAKING

\begin{abstract}
:
Frequently and accurately discerning others' thoughts and feelings is associated with multiple valued educational outcomes across an array of settings. Despite its foundational role in social interactions, it is unclear whether individuals can be taught to improve their social perspective taking capacities. This experiment assesses whether a curriculum taught to U.S. Army personnel $(N=116)$ improved their social perspective taking prior to deployment. Results showed that participants improved their social perspective taking in three ways: through more accurately detecting biases in others, by generating more initial hypotheses to explain others’ behaviors, and by adapting their hypotheses in the face of new evidence. The curriculum did not affect participants' perspective taking accuracy on a video measure. We discuss these findings with respect to their implications for other learning environments.
\end{abstract}

Keywords: social perspective taking, social cognition, interpersonal understanding, bias, person perception 


\section{Teaching Social Perspective Taking: How Educators might Learn from the Army}

"Think about what it's like to be sitting in that audience, in a sea of people, when the professor is so far away he's a dot and I'm looking at overhead transparencies. What is that experience like?"

-- Professor Edward Burger, winner of the 2010 Cherry Award for best college professor in the country (Riley, 2009)

"I was never given classes on how to sit down with a sheik that 2 days before I had seen his face on CNN, and now all of a sudden I am talking to this guy face-to-face. He is providing food for myself and soldiers out in the trucks that are providing security for us while we are having our meeting in this guy's house ... I don't know if he is trying to gain favor with me because he wants something ... is it something good or something bad? It is just something you are going to have to learn on the job and how to deal with."

-- Leonard Wong (2004)

Accurately understanding another person is a vital capacity within educational settings. Teachers who more frequently and accurately "read” their students should better: understand the classroom experience from the point of view of a student in the back of a lecture hall, anticipate which lesson plans will best motivate which students, and infer students' level of understanding from their class participation. This same capacity appears important for a host of student outcomes. In classroom settings, students who are better perspective takers generally receive higher grades (Gehlbach, 2004b), are more cooperative with peers (Johnson, 1975), and maintain better relationships with their teachers(Gehlbach, Brinkworth, \& Harris, 2011).

As important as perspective taking is in educational settings, this capacity may matter even more on the front lines of political conflicts. Accurately anticipating others' reactions, gauging their honesty, and inferring their motivations can make the difference between productive or harmful resolution of conflicts. Research in this domain indicates that better perspective takers tend to be better at resolving disagreements (Corcoran \& Mallinckrodt, 2000), less aggressive (Richardson, Green, \& Lago, 1998), and less likely to stereotype others (Galinsky \& Moskowitz, 2000).

Despite social perspective taking's fundamental importance to a broad range of outcomes, it is unclear whether this capacity can be taught or whether, as Wong states, it is “just something you are going to have to learn on the job.” In classroom and conflict contexts alike, a 
learn-as-you-go approach to figuring others out can cause misunderstandings, escalate conflicts, and damage relationships. This study investigates whether individuals might be taught to improve their social perspective taking capacities. In addition, we examine the extent to which selected dispositional and experiential factors matter.

Specifically, we experimentally tested the efficacy of a classroom-based curriculum designed to teach social perspective taking to United States Army personnel. Many of our participants were deploying to Iraq or Afghanistan to work directly with host nation counterparts to facilitate reconstruction projects or help transition certain responsibilities from the U.S. Army to locals. Thus, the need to perceive these counterparts accurately and without bias - despite substantial cultural differences - was of paramount importance. A primary motivation for this research included the possibility that lessons extracted from teaching social perspective taking in this context might be applied to an array of educational contexts.

We begin by defining and conceptualizing social perspective taking - particularly with respect to the role of bias in perceiving others. Next, we review past research that might inform the teaching of social perspective taking. After describing our curriculum and our pre-post experimental design, we demonstrate the effect of the curriculum on four social perspective taking outcomes. In closing, we discuss the role of our curricular intervention, dispositional confidence, and prior experience as well as the potential implications of our findings for other educational settings.

\section{Social Perspective Taking and Biases}

Social perspective taking encompasses the process of discerning the thoughts, feelings, and motivations of others as well as ascertaining others' points of view and how they perceive the situation. The process begins when a "perceiver" is motivated to take the perspective of a "target” and then collects information from which to make inferences about the target. The accuracy of the inferences depends on: the perceiver's motivation and ability, various characteristics of the target (e.g., how "readable" s/he is), and the larger context in which the perspective-taking episode occurs (Gehlbach, 2004a). Moreover, different types of social perspective taking exist: A perceiver may try to take the perspective of a target while interacting with or observing the target "in the moment" or by reflecting on a past social interaction or observation. 
Based on several conceptualizations of social perspective taking (e.g., Davis, 1996; Gehlbach \& Brinkworth, 2008; Ickes, 2003), teaching this capacity could take any combination of three approaches - motivating perceivers to engage in the process of "reading” others more frequently, improving person-perception skills to enhance the accuracy of perceivers' inferences, or developing perceivers' abilities to recognize and mitigate biases. The role of biases in social perspective taking warrants further clarification. In general, perceivers are motivated to accurately perceive and understand others. However, this core motive can be derailed by two broad, competing motives: maximizing cognitive efficiency or enhancing their sense of self (Gehlbach \& Brinkworth, 2008). In other words, people are generally motivated to see those in their social world as they really are, but sometimes one of two types of biases derail this goal of accurate perspective taking.

In this research, we focus on four such biases that are particularly likely to undermine accurate person perception. Ross and his colleagues' work on the fundamental attribution error (Ross, 1981; Ross, Amabile, \& Steinmetz, 1977) illustrates a bias which allows perceivers to preserve cognitive effort. The “error” is perceivers' pervasive tendency to under-appreciate the power of the situation in explaining targets' behaviors. Instead, perceivers attribute others' behaviors disproportionately to personal traits. Though efficient, this cognitive strategy often diminishes perceivers’ accuracy.

Several other biases facilitate the goal of enhancing one's sense of self. Ross and Ward (1996) describe naïve realism - a bias in which perceivers presume they see the world as it truly is and expect other rational beings to see the world similarly. To the extent that others' perceptions differ, perceivers will assume the others are: too lazy to properly process the information, biased, or subject to different (usually inferior) information. Research on intergroup bias indicates that people generally prefer other members of their own in-group while often exhibiting prejudice against out-group members (Hewstone, Rubin, \& Willis, 2002) thereby maintaining their sense of self through group affiliation. Others (e.g., Wason, 1960) have documented that people tend to remain convinced of their own "pet theories.” After formulating an initial theory, they often selectively focus only on information that confirms their beliefs. Confirmation bias can be particularly destructive in classrooms when teachers develop negative beliefs about students, which can then turn into self-fulfilling prophecies (Brophy, 1983; Rosenthal \& Jacobson, 1968). In sum, we are biased towards enhancing our sense of self 
by thinking that we see the world more accurately than others, the groups we belong to are more desirable than groups we are not a part of, and our pet theories about our social world tend to be correct.

\section{Teaching Social Perspective Taking}

Given the importance of social perspective taking for so many outcomes across multiple contexts, ascertaining whether this capacity might be taught seems critically important. Past studies signal the viability of improving social perspective taking through the aforementioned pathways: enhancing motivation, improving accuracy, or mitigating bias. Through simple manipulations, many studies have successfully motivated participants to engage in the social perspective taking process. For instance, Batson, Early, and Salvarani (1997) encouraged some participants to imagine how a perspective taking target felt, while others imagined how they would feel in the target's situation. They found that imagining how others felt led to altruistic behavior. Galinsky and Moskowitz (2000) asked participants in a perspective taking condition to write about a "day in the life" of the perspective taking target. Motivating participants to engage in perspective taking in this way reduced stereotyping of the targets in question.

Other approaches have attempted to improve perceivers’ accuracy. Ekman and some of his colleagues (e.g., Ekman \& Friesen, 2003) have developed guidelines to help perceivers correctly identify facial expressions of emotion in photographs. In focusing on social perspective taking accuracy more broadly (i.e., examining videos of interactions rather than still photos of emotions), Marangoni, Garcia, Ickes, and Teng (1995) found that providing perceivers with feedback improved their accuracy on later tasks. A multitude of scholars have tried to figure out ways that perceivers might be taught to identify when a target is lying - though with less success in this domain (Kenny \& DePaulo, 1993).

Finally, some scholars have developed manipulations to help participants counteract common biases. For example, Griffin, Dunning, and Ross (1990) asked participants to make different types of social predictions (e.g., How much money would you spend on a celebratory dinner in the city? How unusual are certain personal traits for a student at your institution?). By asking some participants to develop an alternative interpretation of the situation, the authors significantly reduced participants' confidence in their social predictions. The authors describe how this reduced confidence should lead perceivers to have more questions about the situation, seek more information about targets, and, consequently, make more accurate inferences. In a 
related approach, Lord, Lepper, and Preston (1984) found that encouraging participants to “consider the opposite” when trying to learn about the personalities of a target ameliorated confirmation bias.

In sum, experimental manipulations have been developed to improve participants' social perspective taking in specific laboratory contexts, thereby enhancing their performance on desired outcomes. However, (with the potential exception of Ekman's guidelines for recognizing emotions in photographs) because these were merely manipulations, the odds seem small that these interventions might have a lasting impact on participants' social perspective taking capacity. Thus, an open question remains as to whether social perspective taking can be learned through instruction, or whether, as Wong asserts, reading others is something you must pick up through experience. In this article, we examine this testable hypothesis of whether social perspective taking can be taught and learned. Although curricula exist to develop basic perspective taking capacities in those on the autism spectrum, to our knowledge no prior research has attempted to teach typical perceivers to improve their social perspective taking aptitude at a broad, fundamental level.

\section{A Social Perspective Taking Curriculum}

From this research using social perspective taking manipulations, our research team designed a curriculum to teach U.S. Army personnel to be more frequent, more accurate, and less biased perspective takers. Drawing heavily from the aforementioned literature, our curriculum encouraged Soldiers to follow a three-step procedure for taking the perspective of others.

In the initial “assessment” step, we trained participants to detect the aforementioned biases in themselves, in the targets with whom they were interacting, and in their perceptions of the situation. For instance, as an example of a bias they might detect in themselves, they could determine whether they were overly convinced that their perception of the situation was “correct” (i.e., naïve realism). To enhance their accuracy in perceiving others, we taught them three heuristics: trying to focus on changes from targets' baseline behavior (Kenny \& DePaulo, 1993), that people who tend to feel more comfortable or more powerful in a situation often take up more space (Carney, Cuddy, \& Yap, 2010), and that stressed targets often cope by rubbing their hands or neck or touching their face more frequently (Navarro, 2008). Finally, to bolster their motivation to engage in social perspective taking, participants listened to audio recordings 
of stories from deployed Soldiers to illustrate the hazards of not paying sufficient attention to the situation.

In the second step, Soldiers created multiple guesses (i.e., developed multiple hypotheses) as to why the target in question was thinking or behaving in a particular way. In particular, we encouraged our participants to counteract any biases they might perceive in themselves by developing multiple hypotheses (Griffin, et al., 1990; Lord, et al., 1984).

Finally, participants revisited the assessment step to collect information that would specifically help them test certain hypotheses. For example, in a situation where a perceiver was unsure whether the target in question was irritated or nervous about an upcoming event, the perceiver could gather more information about the target's emotional state (perhaps by focusing on facial expressions, tone of voice, or how much space the person took up) or situational constraints (perhaps by thinking through the target's other responsibilities that day). Once participants felt that it was appropriate, they selected an appropriate course of action.

The curriculum's pedagogy included lecture, discussion, bias identification from Soldier's descriptions of misunderstandings in cross-cultural settings, and sharing personal experiences of observing biases in themselves or in others. We modeled much of the “assess/create guesses/select a course of action” process through two video-based cases in which participants followed a protagonist through several episodes of problematic interpersonal communication. The videos included several stopping points for discussions about the types of inferences participants were making about the actors, their guesses about the underlying reasons for different actors behaviors, and how those guesses changed based on new information learned since the previous stopping point. The course lasted approximately six hours which was divided over two days.

\section{Research Questions}

Using this curriculum we conducted classroom-based experiment with a pre-post design. Randomly assigning Soldiers to condition allowed us to make causal inferences about the efficacy of the curriculum. Specifically, we hypothesized that those in the treatment group would:

1) Be more accurate in detecting biases in others,

2) Generate more initial hypotheses to explain why others were behaving as they were,

3) Be more likely to change these hypotheses in the face of new evidence, and 
4) Be more accurate in reading others in a video-based task.

\section{Methods}

\section{Participants}

Our participants $(N=116)$ came from the three different U.S. Army installations. They were $95 \%$ male; $69 \%$ identified as White, $10 \%$ as Latino, and $14 \%$ as African-American. This sample included 53 officers, 53 non-commissioned officers, and 10 civilians. The civilians were expecting to be embedded within Army units for deployment overseas. Participants' education levels ranged from high school graduates to Ph.D.s, with the mean of 3 years of college. On average, the participants had served over 11 years in the Army and had spent almost $2 \frac{1}{2}$ years on deployments.

\section{Measures}

We employed an experimental design with pre- and post-assessment measures. For the pre-assessment, participants completed a survey, a case-based scenario with embedded assessment tasks, and a video-based social perspective taking accuracy task. In addition to basic demographic questions about participants' level of education, years of service, and number of deployments, the survey included scales to assess several dispositions related to participants' social perspective taking. Because self-efficacy is a robust predictor of ability across many domains (Bandura, 1997), we focused on social perspective taking confidence, or participants' sense of efficacy in "reading" others in their daily interactions in this article. This 6 item scale ( $\alpha=.90$ ) consisted of items such as, "In general, how confident are you that you can accurately guess what motivates another person?” and was adapted from (Gehlbach, Brinkworth, \& Wang, in press). Participants responded by positioning a slider bar on a continuum between "not at all confident” (scored as 0) and “extremely confident” (scored as 100).

To assess three of our main measures, we developed two case-based scenarios. These multi-media cases included text, illustrative photographs, and an audio narration. Participants worked on the cases on individual computers with headsets. In each scenario, participants followed the story of a protagonist through a series of events and responded to questions about other characters in the story at each of three different stopping points. These scenarios were composites of real events reported by Soldiers who had served overseas. One storyline followed a Soldier trying to deliver mosquito netting to families in Afghanistan; the other focused on a Soldier who was trying to facilitate construction of a new school in a Kenyan village. Two 
scenarios were developed so that participants could complete one at pre- and the other at postassessment. The scenarios provided measures of participants' capacities to detect biases, come up with multiple hypotheses, and then counteract confirmation bias by adapting their hypotheses in the face of new evidence:

1) Bias detection - We developed a test in which participants identified which biases of certain characters affected the social interactions in the scenario. At each of the three stopping points, participants assessed four highlighted sections of text and were asked to identify whether the fundamental attribution error, naïve realism, in-group/outgroup bias, confirmation bias, or "none of these biases” were present. (Definitions of each bias were provided to ensure that the task assessed detection rather than knowledge of these biases.) Participants' scores represented the percentage of correctly identified biases out of 12 opportunities (3 stopping points with 4 questions per stopping point).

2) Initial hypotheses - For this measure, at the first stopping point in each scenario, participants generated as many hypotheses as they could to explain why a particular character in the scenario was behaving in a certain way. Initial hypotheses scores for each participant consisted of the total number of hypotheses generated at this first stopping point.

3) Adapted hypotheses - At the subsequent two stopping points participants' previous hypotheses were presented again, and participants could retain, revise, delete, or add new hypotheses based on new developments in the scenario since the last stopping point. Thus, adapted hypotheses represented the number of hypotheses that were revised, deleted, or added at these final two stopping points. This measure assessed how likely participants were to incorporate new information into hypotheses regarding the particular character in question.

We developed these cases and the corresponding measures through an extensive, iterative, year-long program of pilot-testing using similar Army populations to the one participating in this study.

To assess social perspective taking accuracy, we used Gehlbach, Brinkworth, and Wang's (in press) measure. Participants watched videotaped conversations of different pairs of people 
discussing various topics. Immediately following each conversation, participants identified whether or not each person had experienced the thoughts and feelings that were listed on a checklist of possible emotions and thought statements. Participants' responses were scored against the self-reports of the individuals who had the conversations in the videos. Thus, participants' scores consisted of the overall percentage of correctly identified thoughts and feelings from the four videos that they watched.

For the post-assessment, participants completed the opposite scenario from the one they completed for the pre-assessment. In other words, after randomly assigning participants to treatment and control groups, we randomly assigned them to take either the Afghan or Kenya case first. For the post-assessment, participants also completed the same video-based social perspective taking accuracy measure (i.e., viewed and responded to the same four videos). The survey items were not re-administered. On average, participants completed the pre-assessment in 45 minutes (and took slightly less time on the post-assessment).

\section{Procedure}

Because two sites did not wish to withhold the curriculum from any participants, we incorporated a specialized data collection procedure into our pre-post experimental design. After randomly assigning participants to treatment and control conditions, all participants took a computer-based assessment battery as their pre-assessment. After a break, the control group returned to the computers to take the post-assessment. Over the next two days, the curriculum was taught to both treatment and control groups. At the culmination of the curriculum, the treatment group then took the post-assessment. In other words, the control group took the preassessment, then post-assessment, and then the curriculum; the treatment group took the preassessment, then the curriculum, and then post-assessment. At the third site, both groups took all assessments at the same time but the control group participated in a separate, unrelated study while the curriculum was administered. At the first two sites, the curriculum was taught by members of the research team; at the third site it was taught by an instructor unaffiliated with the project.

\section{Results}

Before investigating the effect of our curriculum on participants’ bias detection, the number of initial hypotheses they generated, how frequently they adapted hypotheses, and their social perspective taking accuracy, it is helpful to have a descriptive sense of the raw scores for 
the main dependent variables that we had to standardize. On average, participants got roughly half of the bias questions correct $\left(M_{\text {Afghan }}=.44, s d=.18 ; M_{\text {Kenya }}=.52, s d=.21\right)$. In generating initial hypotheses, participants averaged between two and three $\left(M_{\text {Afghan }}=2.39\right.$, $s d=1.40 ; M_{\text {Kenya }}$ $=2.66, s d=2.37$ ) per case. They adapted these hypotheses based on new evidence with some frequency $\left(M_{\text {Afghan }}=1.92, s d=1.98 ; M_{\text {Kenya }}=2.62, s d=3.03\right)$.

Because the scenario based measures were unlikely to be strictly parallel, we had to equate participants' scores in some way. To do so, we standardized these raw scores of participants within scenario - i.e., the scores of participants who completed the Afghan scenario first and the Kenya scenario second were standardized in one group; those who completed the Kenya scenario and then the Afghan scenario were standardized in a second group. By converting each participants' scenario scores into z-scores in this way, we could assess changes between treatment conditions from pre to post even if the two scenarios differed in their difficulty level. Because prior testing with the social perspective taking accuracy measure revealed no practice effects (i.e., people did not improve merely by taking the test) we used the same measure pre and post, and were able to use raw scores (in this case, the proportion of correct answers).

Two additional observations are noteworthy in Table 1. First, contrary to most of the self-efficacy literature, social perspective taking confidence was unrelated to, or negatively associated with, the social perspective taking outcomes. Second, among the variables that addressed participants’ prior experiences, their level of education had a different pattern of associations than their years of service and number of deployments.

$* * * * * * * * * * * * * * * * * * * * * *$

Insert Table 1 about here

We first analyzed our data using multi-level models with maximum-likelihood estimation due to the nesting of participants within site and instructor(s). There was no effect of nesting for our full models. Thus, we present our results as ordinary least-squares regression models and include adjusted- $R^{2}$ statistics to document how much variability each model explained. Table 2 presents a basic model (the odd-numbered models) that includes participants' scores on the relevant pre-measure as a covariate and their experimental condition; in the full models (the even-numbered models) we also included participants' social perspective taking confidence, 
level of education, years of service, and number of deployments. For each model we also report the adjusted- $R^{2}$ value when treatment was removed as a predictor. The difference in the two adjusted- $R^{2}$ values represents the percentage of unique variance explained by the treatment.

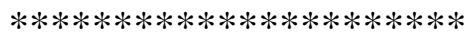

Insert Table 2 about here

As Table 2 indicates, participation in the curriculum improved participants' ability to detect bias in others, generate initial hypotheses, and adapt their hypotheses as new evidence emerged. The curriculum had no discernable impact on participants' accuracy in reading others as measured by our video task. The treatment accounted for between 4 and $11 \%$ of the variance in these outcomes. Although these effects signaled an overall positive impact of the curriculum, we were concerned that, for some outcomes, the curriculum may have simply motivated treatment participants to try harder on the post test, i.e., without improving their actual social perspective taking capacity. For example, perhaps the curriculum simply motivated participants to write more when they were developing their hypotheses Follow-up analyses examining the number of words that participants wrote per hypothesis showed no differences between the treatment and control conditions $\left(t_{106}=.19, n s\right)$. Thus, it seems reasonable to conclude that the curriculum's effect went beyond merely encouraging participants to write more.

Table 2 also indicates that social perspective taking confidence and years of service in the Army were negative predictors of certain outcomes. Meanwhile, participants' level of education and number of deployments were positive predictors of certain outcomes. Thus, participants' dispositions and prior experiences did not always have the effects we anticipated on our outcomes. Furthermore, the experiential effects appeared to differ based on the type of prior experience.

\section{Discussion}

Our data clearly indicate that some types of social perspective taking are teachable and do not have to be relegated to being learned “on the job.” At the same time, a dispositional factor and certain prior experiences also appear to be associated with several outcomes. We discuss each of our hypothesized outcomes in turn.

\section{Accuracy in Detecting Biases}


The capacity to detect biases allows individuals to sense and potentially mitigate the biases' influence on social interactions. Exposure to the curriculum helped participants detect four biases - the fundamental attribution error, naïve realism, intergroup bias, and confirmation bias - that disrupt accurate person perception. Of the other factors that we investigated, exposure to our curriculum was the only one associated with improvements on this outcome.

\section{Generation of Initial Hypotheses}

People's skills at detecting biases are useful to the extent that they can then do something to counteract the bias. The curriculum focused explicitly on encouraging participants to develop and assess multiple hypotheses regarding why a target seemed to be behaving as he or she was. The curriculum had its biggest effect on this outcome, explaining $11 \%$ of the unique variance in participant's capacity to develop multiple hypotheses. Participants' educational level was also associated with this outcome - more educated participants generated more initial hypotheses. Although most of the U.S. educational system does not focus explicitly on improving students' social perceptions, this correlational finding signals that educational attainment may provide some collateral learning benefits that facilitate perceiving and understanding others.

\section{Adapting Hypotheses}

Our curricular focus on encouraging participants to develop multiple hypotheses is presumably most effective provided that perceivers avoid becoming so attached to these hypotheses that they ignore relevant new evidence (i.e., confirmation bias). After exposure to our curriculum, participants significantly improved in this capacity. In both the descriptive correlations and our full regression model, more confident perspective takers were less likely to adapt their working hypotheses about others. Although most prior findings have indicated that confidence is unrelated to accuracy (e.g., Ames \& Kammrath, 2004), our finding indicates that confidence (or perhaps over-confidence) may actually hinder some aspects of social perspective taking. As with the previous outcome, educational attainment was positively associated with improved capacity to adapt hypotheses. This result reinforces the possibility that higher educational attainment may be associated with some aspects of improved social perspective taking.

\section{Social Perspective Taking Accuracy}

Our final outcome assesses “in-the-moment” perspective taking rather than the more "reflective” perspective taking tasks from the scenarios. We found no effect of the curriculum 
on this outcome. Many explanations are possible: perhaps our guiding heuristics were ineffective or were forgotten by the time of the post assessment administration; maybe we allocated insufficient time for participants to practice with the heuristics; and so on. Because this type of social perspective taking is critical for so many interpersonal situations, developing ways to help individuals improve their accuracy in this domain will be important. Despite the null effects of the curriculum, we found that participants' years of service had a slight negative effect on this outcome. This finding was a suppressor effect (Rosenberg, 1968) - i.e., the simple correlation showed no association; the statistical relationship only emerged after accounting for other factors. Conversely, Soldiers who had been deployed more tended to be more accurate. Although it is premature to draw conclusions from an isolated, correlational finding, it is interesting to speculate that perhaps (after accounting for other factors), deployments are associated with improved accuracy because they expose Army personnel to a greater number and greater diversity of perspective taking targets. By contrast, perhaps remaining in the Army (particularly without being deployed) increases one’s reliance on protocols to guide social behavior and obviates the need to accurately read others. These possibilities warrant future investigation.

In sum, our findings indicate social perspective taking is not something that can only be learned on the job. At the same time, our data suggest that different types of experiences in different contexts may facilitate (or inhibit) the development of this capacity. Thus, social perspective taking may be something that can also be learned on the job to some degree.

\section{Limitations and Future Directions}

Before assessing the potential implications of these findings, several limitations are important to note. Perhaps the most salient limitation is that our outcome measures derive from scenarios presented on computers rather than from actual social interactions. Needless to say, deploying the research team to multiple war zones to track our participants' social interactions after they completed the curriculum was beyond the scope of the study. We were also limited in the different types of social perspective taking that we could afford to investigate. Ultimately, we also want to know how to make perceivers more accurate when they interact with targets (not just when they reflect upon or observe them). In addition, because many participants deployed shortly after the study, we could not assess the longevity of the treatment effects. 
Despite these limitations, impacting key aspects of social perspective taking accuracy after a brief, six hour curricular intervention is an encouraging result for those interested in teaching this capacity. In thinking about developing this intervention further, schools seem like an especially promising context. Because students tend to return to school daily (rather than deploying world-wide) and interact with many of the same targets repeatedly, there may be more opportunities to assess multiple types of social perspective taking with actual targets over time. Field experiments in schools could test the efficacy of revised curricula and/or more localized manipulations.

\section{Implications for the Army and for Other Learning Contexts}

The implications of these findings for the U.S. Army are clear - social perspective taking is a capacity that can be improved through instruction. To the extent that Army personnel continue to collaborate with host nation counterparts, developing this capacity in conjunction with culture-specific knowledge is critical. Our data also suggest that dispositional and experiential factors may affect individuals’ social perspective taking capacities. More precisely identifying those dispositions and experiences, ascertaining whether they play a causal role in perspective taking outcomes, and enhancing the efficacy of the curriculum, seem like important next steps.

Because of the importance of social perspective taking, it seems essential to consider the potential implications of teaching this capacity within more traditional learning contexts so that this aptitude might be developed among all students and their teachers. Most classrooms are rife with opportunities and needs for improved social perspective taking. On a daily basis, teachers face the problem of too much knowledge in which they must understand what it is like for their students to not understand the subject matter that, as teachers, they understand thoroughly. Students' fitness for the increasingly global society that they inhabit depends critically upon their abilities to interact with and understand a diverse range of individuals. Principals and other school leaders must anticipate how different constituent groups will react to potential policy changes.

One implication of our findings for more traditional school environments is that confidence in one’s social perspective taking capacity may be more of a liability than previously understood. Previous research indicates that confidence in one's social perspective taking ability is usually unrelated to accuracy (Ames \& Kammrath, 2004). However, the present research 
indicates that more confident perspective takers may be less likely to adapt their hypotheses in light of new evidence. If a causal association is borne out in future studies, there are important implications for teachers. To the extent that teachers feel highly confident that they really understand a student well, they may be less attentive to cues about that student's thoughts, motivations, or affective state and more likely to fall prey to confirmation bias. This could ultimately strain the teacher-student relationship and/or inhibit teachers' capacity to help that student learn. The important implications of this finding make it a priority for future research.

A second area that seems like a particular priority for scholars is the extent to which this training can be maintained or bolstered over time. On the one hand, it seems likely that the passage of time should only serve to weaken the effects of the intervention. On the other hand, because this curriculum is designed to intervene at the level of social interactions, positive recursive cycles might also be sparked (Cohen \& Garcia, 2008). For example, if a teacher catches herself committing the fundamental attribution error with a student, she may pause and ask the student for his view of the situation. This act might produce a greater understanding of how the situation looks from the student's perspective. In turn, this understanding might result in the teacher interacting with the student in a more positive manner. Remembering this more positive interaction, the student might be more inclined to give the teacher the benefit of the doubt in their next encounter... and so on. To the extent that these cycles become positively reinforcing for teachers and students, it is possible that this type of intervention might have relatively long-lasting effects. Knowing the duration and trajectory of the effects of this social perspective taking curriculum also seems like a priority for future research in more traditional schooling environments.

Having established social perspective taking as a teachable capacity raises the possibility that professional development sessions for teachers might help them more accurately read and redress students' motivational or engagement challenges; reduce the bias with which they view students; enhance their relationships with students - which we know to be associated with numerous positive youth outcomes (Juvonen, 2006); and better manage the problem of too much knowledge to facilitate student learning. The possibility of teaching students to improve their social perspective taking could have equally powerful benefits for their teacher-student relationships, improve peer relationships, reduce conflict and violence in schools, and endow students with a greater appreciation of perspectives that diverge from their own. Furthermore, if 
Running head: TEACHING PERSPECTIVE TAKING

social perspective taking were taught in schools, its benefits might be realized broadly across the entire population.

Social perspective taking affects our most critical social interactions. Improving this capacity will benefit individuals across multiple contexts - from conflicts to classrooms - and on multiple outcomes. To be sure, much work lies ahead in ascertaining how to best teach this important capacity and which related dispositions we may wish to cultivate. However, given evidence that it can be taught, can we afford not to further investigate the potential benefits of doing so? 


\section{References}

Ames, D., \& Kammrath, L. (2004). Mind-reading and metacognition: Narcissism, not actual competence, predicts self-estimated ability. Journal of Nonverbal Behavior, 28(3), 187209.

Bandura, A. (1997). Self-efficacy: The exercise of control. New York: W.H. Freeman.

Batson, C. D., Early, S., \& Salvarani, G. (1997). Perspective taking: Imagining how another feels versus imagining how you would feel. Personality and Social Psychology Bulletin, 23(7), 751-758.

Brophy, J. E. (1983). Research on the self-fulfilling prophecy and teacher expectations. Journal of Educational Psychology, 75(5), 631-661.

Carney, D. R., Cuddy, A. J. C., \& Yap, A. J. (2010). Power posing: Brief nonverbal displays affect neuroendocrine levels and risk tolerance. Psychological Science, 21(10), 13631368.

Cohen, G. L., \& Garcia, J. (2008). Identity, belonging, and achievement: A model, interventions, implications. Current Directions in Psychological Science, 17(6), 365-369.

Corcoran, K. O., \& Mallinckrodt, B. (2000). Adult attachment, self-efficacy, perspective taking, and conflict resolution. Journal of Counseling \& Development, 78(4), 473-483.

Davis, M. H. (1996). Empathy: A social psychological approach. Boulder: Westview Press.

Ekman, P., \& Friesen, W. V. (2003). Unmasking the face: A guide to recognizing emotions from facial clues. Cambridge: Malor.

Galinsky, A. D., \& Moskowitz, G. B. (2000). Perspective-taking: Decreasing stereotype expression, stereotype accessibility, and in-group favoritism. Journal of Personality and Social Psychology, 78(4), 708-724.

Gehlbach, H. (2004a). A new perspective on perspective taking: A multidimensional approach to conceptualizing an aptitude. Educational Psychology Review, 16(3), 207-234.

Gehlbach, H. (2004b). Social perspective taking: A facilitating aptitude for conflict resolution, historical empathy, and social studies achievement. Theory and Research in Social Education, 32(1), 39-55.

Gehlbach, H., \& Brinkworth, M. E. (2008). Motivated thinkers and the mistakes they make: The goals underlying social cognitions and their consequences for achievement. In M. L. 
Running head: TEACHING PERSPECTIVE TAKING

Maehr, S. Karabenick \& T. Urdan (Eds.), Advances in motivation and achievement: Social psychological perspectives. (Vol. 15, pp. 119-144). Bingley, UK: Emerald.

Gehlbach, H., Brinkworth, M. E., \& Harris, A. D. (2011, April). Social perspective taking as a potential facilitator of teacher-student relationships. Paper presented at the American Educational Research Association, New Orleans.

Gehlbach, H., Brinkworth, M. E., \& Wang, M.-T. (in press). The social perspective taking process: What motivates individuals to take another's perspective? Teachers College Record.

Griffin, D. W., Dunning, D., \& Ross, L. (1990). The role of construal processes in overconfident predictions about the self and others. Journal of Personality and Social Psychology, 59(6), 1128-1139.

Hewstone, M., Rubin, M., \& Willis, H. (2002). Intergroup bias. Annual Review of Psychology, 53(1), 575-604.

Ickes, W. J. (2003). Everyday mind reading: Understanding what other people think and feel. Amherst, NY, US: Prometheus Books.

Johnson, D. W. (1975). Cooperativeness and social perspective taking. Journal of Personality and Social Psychology, 31, 241-244.

Juvonen, J. (2006). Sense of belonging, social bonds, and school functioning. In P. A. Alexander \& P. H. Winne (Eds.), Handbook of educational psychology. (pp. 655-674). Mahwah, NJ, US: Lawrence Erlbaum Associates Publishers.

Kenny, D. A., \& DePaulo, B. M. (1993). Do people know how others view them? An empirical and theoretical account. Psychological Bulletin, 114(1), 145-161.

Lord, C. G., Lepper, M. R., \& Preston, E. (1984). Considering the opposite: A corrective strategy for social judgment. Journal of Personality and Social Psychology, 47(6), 1231-1243.

Marangoni, C., Garcia, S., Ickes, W., \& Teng, G. (1995). Empathic accuracy in a clinically relevant setting. Journal of Personality and Social Psychology, 68(5), 854-869.

Navarro, J. (2008). What every body is saying. New York: Harper-Collins.

Richardson, D. R., Green, L. R., \& Lago, T. (1998). The relationship between perspective-taking and nonaggressive responding in the face of an attack. Journal of Personality, 66(2), 235256. 
Riley, N. S. (2009). America's Top College Professor. The Wall Street Journal. Retrieved from http://online.wsj.com/article/SB10001424052748704402404574524402818418042.html

Rosenberg, M. (1968). The logic of survey analysis. New York, Basic Books.

Rosenthal, R., \& Jacobson, L. (1968). Pygmalion in the classroom; teacher expectation and pupils' intellectual development. New York: Holt Rinehart and Winston.

Ross, L. (1981). The "intuitive scientist" formulation and its developmental implications. In J. H. Flavell \& L. Ross (Eds.), Social cognitive development: Frontiers and possible futures (pp. 1-42). Cambridge: Cambridge University Press.

Ross, L., Amabile, T. M., \& Steinmetz, J. L. (1977). Social roles, social control, and biases in social-perception processes. Journal of Personality and Social Psychology, 35(7), 485494.

Ross, L., \& Ward, A. (1996). Naive realism in everyday life: Implications for social conflict and misunderstanding. In E. S. Reed \& E. Turiel (Eds.), Values and knowledge (pp. 103-135). Mahwah: Lawrence Erlbaum Associates Inc.

Wason, P. C. (1960). On the failure to eliminate hypotheses in a conceptual task. The Quarterly Journal of Experimental Psychology, 12, 129-140.

Wong, L. (2004). Developing adaptive leaders: The crucible experience of operation Iraqi Freedom. Carlisle, PA: Strategic Studies Institute. 
Running head: TEACHING PERSPECTIVE TAKING

Table 1: Means, standard deviations, and correlations for the dependent measures (numbers 1-4) and covariates (numbers 5-8).

\begin{tabular}{|c|c|c|c|c|c|c|c|c|c|c|c|c|c|}
\hline & $N$ & Mean & sd & Min. & Max. & $\begin{array}{c}r \text { with } \\
\text { Pre- } \\
\text { Measure }\end{array}$ & 1 & 2 & 3 & 4 & 5 & 6 & 7 \\
\hline 1) Bias detection & 114 & .00 & .98 & -2.09 & 2.34 & $.30 * *$ & -- & & & & & & \\
\hline 2) Initial hypotheses & 110 & -.11 & .86 & -1.62 & 3.53 & $.40 * * *$ & $.18 \dagger$ & -- & & & & & \\
\hline 3) Adapting hypotheses & 110 & .00 & 1.00 & -.94 & 3.26 & $.32 * * *$ & $.24 *$ & $.45 * * *$ & -- & & & & \\
\hline 4) SPT accuracy & 115 & .66 & .08 & .42 & .83 & $.57 * * *$ & .06 & .03 & .00 & -- & & & \\
\hline 5) SPT confidence & 115 & 57.20 & 15.99 & 20.67 & 96.67 & & .03 & $-.18 \dagger$ & $-.20 *$ & .02 & -- & & \\
\hline 6) Level of education & 114 & 15.46 & 2.16 & 12 & 18 & & .12 & $.26 * *$ & $.24 *$ & .13 & .11 & -- & \\
\hline 7) Years of service & 115 & 11.56 & 6.61 & 0 & 25 & & -.14 & -.02 & -.04 & -.05 & $-.20 *$ & -.08 & -- \\
\hline $\begin{array}{l}\text { 8) Number of } \\
\text { deployments }\end{array}$ & 115 & 2.43 & 1.41 & 1 & 6 & & $-.16 \dagger$ & -.03 & .01 & $.19 *$ & $-.17 \dagger$ & -.14 & $.43^{* * *}$ \\
\hline
\end{tabular}

$\mathrm{N}$ ranges from 108 to 115 in correlation matrix

" $r$ with Pre-Measure" is the correlation between each dependent measure and the same measure given during the pre-test.

$\dagger p<.10 ; * p<.05 ; * * p<.01 ; * * * p<.001$ 
Table 2: Comparison of standardized regression models predicting each outcome variable including standardized Betas, significance, and adjusted $R^{2}$ values.

\begin{tabular}{|c|c|c|c|c|c|c|c|c|}
\hline & \multicolumn{2}{|c|}{ Bias } & \multicolumn{2}{|c|}{ Initial Hypotheses } & \multicolumn{2}{|c|}{ Adapting hypotheses } & \multicolumn{2}{|c|}{ SPT accuracy } \\
\hline & Model 1 & Model 2 & Model 3 & Model 4 & Model 5 & Model 6 & Model 7 & Model 8 \\
\hline Pre & $.27 * *$ & $.24 *$ & $.40 * * *$ & $.33 * * *$ & $.29 * *$ & $.29 * *$ & $.57 * * *$ & $.55 * * *$ \\
\hline Treatment & $.21 *$ & $.22 *$ & $.34 * * *$ & $.34 * * *$ & $.24 * *$ & $.22 *$ & -.08 & -.08 \\
\hline SPT confidence & & .05 & & -.11 & & $-.21^{*}$ & & .02 \\
\hline $\begin{array}{l}\text { Level of } \\
\text { education }\end{array}$ & & .08 & & $.23 * *$ & & $.25 * *$ & & -.05 \\
\hline Service years & & -.04 & & -.01 & & -.13 & & $-.18^{*}$ \\
\hline Deployments & & -.13 & & -.01 & & .10 & & $.18^{*}$ \\
\hline Adj. $R^{2}$ & .12 & .11 & .26 & .29 & .14 & .22 & .31 & .33 \\
\hline $\begin{array}{l}\text { Adj. } R^{2} \text { without } \\
\text { Treatment }\end{array}$ & .08 & .07 & .15 & .18 & .09 & .17 & .31 & .33 \\
\hline
\end{tabular}

Ns ranged from 107 to 112 for each model.

$\dagger p<.10 ; * p<.05 ; * * p<.01 ; * * * p<.001$

"Pre" variable represents the pre-assessment score for each outcome (i.e., bias score for the pre-assessment in models 1 and 2; initial hypotheses score for the pre-assessment in models 3 and 4; etc.).

“Adj. $R^{2}$ without Treatment” represents the adjusted $R^{2}$ for the same model with Treatment removed - this provides an estimate of how much unique variance is explained by the treatment in each model. 